\title{
[DISCUSSÃO DA MESA COM O PÚBLICO]
}

Ivan Domingues: Obrigado, agora vai ser uma nova etapa aqui no Painel. Eu acho que o João vai ter que sair, ele está pedindo licença... Nem precisa perguntar qual é o motivo. Vou fazer uma proposta... Primeiro, perguntar se a mesa quer interagir, alguém tem alguma pergunta a fazer, quer polemizar... interagir uns com os outros. Assim, eu daria algum tempo para isso e depois, claro!, vai ter uma conversa com a plateia. O limite, eu havia me entendido aqui com o João, a gente sairia daqui até dez para onze. Para podermos acompanhar a sessão de encerramento. Quer dizer, vamos ter tempo suficiente para continuar a conversa aqui. Paulo você tem algo a dizer... Guido, Paulo...

João Carlos Salles: Oh, Ivan... me desculpe, eu tenho que resolver um pequeno probleminha... mas, eu espero vê-los, logo mais... não percam... a Orquestra Rumpilezz... se vocês se emocionaram com Meojibá, vocês vão gostar do refinamento técnico da Rumpilezz, com a marca cultural baiana, muito americana, vocês vão gostar. Desculpem a mesa, mas um abraço.

Paulo Margutti: Eu só queria dizer, eu teria uma resposta a dar para o João. Mas como o João está saindo... Não! Depois eu converso com você em particular. Pode ir. [risos]

Ivan Domingues: Guido tem alguma coisa a dizer... Vinicius...

Vinicius: Eu só queria fazer uma observação muito rápida... Eu acho que essa questão da língua apareceu e reapareceu aqui, no fundo, por quê? Porque é nossa relação com as agências também... competição. Quer dizer, uma coisa que está na pauta é a internacionalização. Em tudo quanto é lugar. Eu achei muito felizes as colocações... Apenas é bom lembrar que de fato pensar é dar forma, estilo... é muito diferente começar o texto como a Marilena fez aqui, uma performance muito provocativa. De fato I shall argue that... e isso já não é traduzir algo para um outro idioma. É dar ao pensamento uma direção, uma forma. E é claro, é interessante a gente saber abrigar formas diferentes 
de pensar. E o idioma é expressão disso. A gente não deve esquecer isso, sem renunciar à nossa própria forma, enfim... Eu nem sei por que estou dizendo isso... Mas eu gostei do que vocês falaram e gostaria de acrescentar.

Ivan Domingues: Marilena, alguma observação?

Marilena Chauí: Não, não. Eu já gritei o que podia. [risos]

Ivan Domingues: Então, antes de passar à plateia, eu gostaria de comentar que a gente vai publicar um dossiê dessa mesa. A revista Kriterion vai publicar lá na UFMG. Então essa conversa aqui hoje vai se transformar num dossiê. Esse dossiê vai ser divulgado em breve. Está sendo gravado, é claro que essa interação aqui, vai aparecer lá nesse dossiê. Antes de passar para a plateia... Rodrigo Duarte, da UFMG, vai se inscrever em primeiro lugar... Eu queria lembrar o seguinte: esse paper acerca dos rankings citado por Marilena, dando conta de uma característica das publicações que está associada ao taylorismo, ao taylorismo acadêmico, que carrega as métricas e redunda nisso, nessa coisa insana, doida. Nessa coisa de sistema, que leva a essa sandice de ranquear sem ler, que está atrás de medidas automáticas... Eu gostaria de dizer que tem outras saídas, podemos pensar em outras saídas... A avaliação tem que ser feita por meio de comitês, com ajuda de relatórios, alguém tem que ler, as pessoas têm que ler... e com a ajuda também de séries históricas, séries relativamente longas, e não mediante instantâneos congelados do tempo, um ano, o ano civil. O sistema inglês há muito tempo achou uma saída, um expediente muito bom, com a avaliação feita de sete em sete anos, o professor indica as quatro, três mais importantes, e aí a coisa é feita nessa base. De olho na qualidade e não na quantidade tão só. Então, há remédios, tem soluções; podemos fazer triagens, podemos fazer seleções, podemos focar na qualidade e não tem muito mistério. A coisa já faz parte das tradições da academia, mas infelizmente nas últimas décadas têm sido deixados de lado aqui no Brasil esses expedientes, essas práticas já conhecidas e testadas. Passo a palavra ao público, Rodrigo já se inscreveu... há um outro ... qual o seu nome?

- Marcelo.

Ivan Domingues: Marcelo... Rodrigo, outro Marcelo, César... Mais? Flávio e Rui. Rodrigo, venha cá, por favor.

Rodrigo Duarte: Bom dia a todas e a todos. Primeiro, eu gostaria de cumprimentar a mesa pelas excelentes colocações e agradecer a oportunidade desse debate, e me parece que subjazendo quase todas as falas, ou não tão subjacente tanto assim, está a questão da internacionalização, da chamada internacionalização, e com a contribuição da Marilena que mostrou isso, bem com uma espécie de autocrítica que um dos responsáveis por esse tipo de "ranqueamento" fez. O que se chama de internacionalização na verdade é uma 
redução a um modelo, a uma língua, a um modelo de se fazer ciência, saber, e etc. etc. Uma coisa que curiosamente chama pouco a atenção nossa é que países com tradição filosófica muito consolidada estão sofrendo pressão com isso. Ou seja, franceses são sabidamente relutantes em falar uma língua que não seja o francês... eles estão tendo, coitados, que quebrar pedra para falar inglês. É uma coisa que eu tenho sentido quando eu vou a congressos internacionais. Então, antes, o francês não falava inglês de jeito nenhum, e eu falo mal francês, quase não falo francês, e então eu ficava tentando me comunicar em alemão, dava certo. Tentava me comunicar em inglês, não dava certo. E agora já está dando... eu achei sintomático isso. Os alemães que têm uma prática com o inglês, graças à sua escola muito boa, eles estão automaticamente se adaptando e publicando, inclusive na Alemanha, cada vez mais em inglês... ou seja, é um processo que está ameaçando, não somente nós aqui, com um tipo de saber [globalizado], no caso aqui a Filosofia, claramente em construção e dando passos interessantes etc. etc. Internacionalização, sim, eu penso. Mas qual internacionalização? Esse modelo de internacionalização é uma coisa totalmente furada e insustentável... Tem um tipo de internacionalização que me interessa muito e que é assim... aproveitando os meios tecnológicos que estão à disposição, tem a ver efetivamente com uma circulação de ideias sem fronteiras e isso, é claro, está muito longe de acontecer numa escala maior, mas começa a acontecer. Existem... eu assisti muito atentamente à palestra da Marilena ontem, criticando exatamente toda a ideia de virtualidade que existe hoje, que em muitos aspectos podem nos ameaçar muito frontalmente, mas é claro que existem recursos muito interessantes, né? Então, eu só queria chamar a atenção... Concluindo, sem me alongar mais, eu gostaria de chamar a atenção para um recurso interessante que é um site, aparentemente sem fins lucrativos; embora haja lá alguns anúncios acadêmicos, eu brinco falando que é uma espécie de facebook acadêmico que é o academia.edu. É muito curioso porque a gente se cadastra, põe um perfil, infelizmente em inglês. Bom! Pode ser em outra língua, mas, efetivamente, é feito em inglês mesmo, e você pode subir papers... e quando eu fui decidir que trabalhos eu subiria para a minha página nesse site, eu escolhi trabalhos em inglês e alemão, em espanhol ou português. É uma coisa curiosa porque dá a medida de uma outra internacionalização possível. É que existe uma ferramenta no site que permite você ver, a partir de que país, estão acessando e baixando seus papers. Muito interessante, não? Eu fiquei muito comovido, como o Vinicius falou, quando eu vi pela primeira vez que baixaram um paper meu da Índia em inglês. Mas eu fiquei mais comovido ainda quando vi que os papers meus em espanhol estavam sendo baixados na América Latina e que nós estávamos começando a quebrar um gelo, nosso, em relação aos países de língua espanhola, nossos 
vizinhos. E ultimamente, aumentando a minha comoção, textos meus em português estão sendo baixados em Portugal, sim, claro. Mas estão sendo baixados também em Moçambique e em Angola.

Marilena Chauí: Isso é muito bom.

Rodrigo Duarte: Sim. Pronto. Essa internacionalização eu quero, eu acho que a gente tem que saudar essa internacionalização, porque aí há uma circulação global de ideias, há um debate efetivamente internacionalizado. Não é isso que está sendo chamado de internacionalização, que é de fato a internacionalização. Obrigado! Desculpe, ter-me alongado.

\section{[aplausos]}

Ivan Domingues: Alguém quer comentar, reagir à fala do Rodrigo... Não? Passo a palavra a Marcelo. Primeiro, eu vou te identificar para registrar: de onde você vem?

Marcelo: Bom dia a todos. Primeiro, eu vou falar do meu lugar, porque a fala da gente às vezes é comprometedora. É que a gente está se despindo quando coloca muito daquilo que a gente pensa. E qual é o meu lugar? Eu sou professor da Universidade Federal do Recôncavo da Bahia, sou formado em Filosofia pela Universidade Federal da Bahia e fiz mestrado em Filosofia por essa mesma Universidade. As pessoas dizem que eu deveria fazer o doutorado. $\mathrm{Eu}$ pretendo fazer um dia o doutorado. E tem um questionamento que as pessoas fazem para mim: o que você pretende fazer? Eu não sei... Eu quero estudar um conceito que eu estou chamando de subjetividade compartilhada. Mas, perguntam, qual autor você está estudando para isso? Aí emperra! Porque eu não quero utilizar um autor. A tese no geral se chama: Deus não é civilizado: modernidade e democracia. É uma discussão que estou fazendo. Não! Você tem que ter um autor e um conceito. Por que eu estou colocando isso? Eu estou colocando isso aqui por causa das falas que eu ouvi aqui, e que estão apontando para uma Filosofia mais criativa, uma Filosofia que pense um problema, que talvez tenha no Brasil uma Pós [inaudível]. Mas a gente não encontra esse espaço em nenhum programa de pós-graduação do país. Então a gente está ampliando essas propostas [de tese]. Se a gente trouxer para a discussão propostas de cunho temático, elas vão ter que ser reduzidas a um autor, qualquer um que seja ele, mas um autor que algum professor daquele programa possa apresentar para a gente. Então eu vou fazer uma provocação à mesa, diante de toda essa discussão que eu vi aqui, em relação a todo esse problema de internacionalização e aquisição de uma outra língua. Então para fazer doutorado eu não posso saber só a língua portuguesa. Isso não cabe. Eu tenho que saber uma outra língua. Quando eu fiz o mestrado, eu fiz inglês, e achei que meu inglês era ruim. Mas, depois de ter entendido completamente o que a professora Marilena Chauí falou aqui no início, eu estou feliz porque 
eu vi que meu inglês não é tão ruim assim. Ou então a professora está falando um péssimo inglês. [risos]

Marilena Chauí: É possível!

[risos]

Marcelo: Então eu confesso que, em parte, eu fiquei muito feliz. Eu estou falando isso... para falar dessa organização espacial que a gente encontra nos programas de pós-graduação no país e dessa hierarquia de onde você quer fazer o seu doutorado, Marcelo? Eu quero fazer na USP ou na UNICAMP? Por quê? Porque é a USP, porque é a UNICAMP, porque é a oitava do ranking... é a que está não sei onde... Que coloca gente que se destaca... Porque se eu fizer na Bahia, novamente... você fez a graduação na Bahia, sua pós-graduação na Bahia... você vai ficar aqui na Bahia? Não, vai para fora e se possível, para outro país. Aí eu já penso em Harvard ou qualquer coisa desse tipo. Não sei se vou chegar lá. Mas a pretensão existe. E os meus colegas de universidade sabem disso porque eu anuncio aos quatros... Gil Franco sabe, ele é testemunha disso, ele é professor e já é Doutor, ele não tem essa preocupação que eu tenho.

Gil Franco: Nem de ir para Harvard.

Marcelo: Nem ir para Harvard. Mas, enfim... Qual a discussão que eu quero colocar. Veja só... muitos estudantes de Filosofia hoje têm essa inquietação, nós estamos pensando em uma História da Filosofia. E eu falo: não é nem [mesmo] a História da Filosofia uma ciência filosófica. Mesmo a História enquanto ciência tem um rigor, eu sou também formado em História, que nós não temos na Filosofia. Nós temos o rigor filosófico. O que eu acho fundamental também. Não é possível a gente criar sem conhecer aquilo que a gente já tem sobre a produção. O domínio do conceito é fundamental. Mas não deveria ser só isso, mas parece que é só isso. A inquietação da mesa, sobretudo na sua fala, né? O que a gente está fazendo é bom? É! Precisa melhorar? Sim! Mudando o objetivo. Eu acho que isso é fundamental. Agora a provocação: por exemplo, a organização do próprio evento, aqui, revela uma epistemologia, em função do lugar que cada temática ocupou nos espaços. Os que estão aqui, os que estão no outro lado, os que estão nos outros hotéis. Isso tudo, no meu entendimento, revelou dentro desta epistemologia uma fixação na relação de poder. $O$ que é fazer Filosofia? Se você pegar a programação, você vai ver que as inscrições conceituais voltadas para a discussão daqueles clássicos tidos como canônicos, estão todos aqui. Aqueles que não são tidos como filósofos... Sei lá! Um Sartre... às vezes, um Heidegger... encosta ali naquela sala, vai pra lá... joga... você está falando sobre religiosidade, não pode... o meu trabalho era sobre modernidade, me colocaram em uma sala com dois padres, não sei... diácono, um padre... uma seita [inaudível]. Eu 
pensei: "Eu estou perdido!" Na hora em que eu falar Deus não é civilizado, esses caras vão partir para cima de mim. Eu acho que passa também por isso. E aí, só para fechar... pedindo desculpa pela demora ... não seria o caso de nós começarmos a pensar, pelo menos, os programas de pós-graduação, mestrado e doutorado... o doutorado ao invés de exigir duas línguas estrangeiras, exigir só uma? Ou nenhuma. Agora que a gente está querendo pensar uma Filosofia, não só no Brasil, mas também uma Filosofia do Brasil. Então, como a gente está falando da valorização da nossa língua, do vernáculo, no entanto a gente vai ter que produzir em língua portuguesa. Mas você só entra no doutorado se você tiver o domínio de pelo menos duas línguas. [O que estou fazendo] é só uma provocação. Nós fazemos isso. E ao fazer isso, a gente também está dizendo: oh, você quer fazer isso, porque depois você vai ter que publicar em outra língua. Sabe qual é a resposta... essa é a questão que eu coloco aqui para vocês... já que é uma instância e vai sair daqui um relatório, como pensar isso? Que língua a gente quer para a gente falar de uma Filosofia do Brasil? É a língua inglesa, francesa, o alemão ou o português? E a partir daí a gente pensa nos nossos programas de pós-graduação. Eu por enquanto só sei duas línguas: a portuguesa e a inglesa da professora Marilena Chaú.

\section{[risos] [aplausos]}

Ivan Domingues: Alguém quer comentar...

Marilena Chauí: Eu quero comentar duas coisinhas: a primeira é que a questão de serem pedidas línguas estrangeiras, tanto no mestrado quanto no doutorado, está ligada ao fato de que seu trabalho vai incluir uma consulta bibliográfica ampla. Você precisa ter acesso a uma bibliografia sobre o assunto. Essa bibliografia pode estar toda em inglês, toda em francês ou toda em italiano... vai haver línguas onde muito do que você precisa está consignado. Pode ser também que você escolha um tema em que a referência a determinados filósofos vai ser indispensável. Você não pode propor, por exemplo, a questão da imanência e fazer de conta que Espinosa não existe. Ou que Levinas não existe. Então o fato de ser temático não significa que você não tem referências a Filosofias determinadas que trataram do tema, e o modo como você vai tomar posição em relação a isso, com o fato de que muito disso está escrito ou na língua do próprio filósofo ou na língua em que ele foi traduzido. O ideal, se você vai falar de imanência e você tem que ir a Espinosa, é que você saiba latim. Isso seria o melhor. Se não der, uma boa tradução. Estamos fazendo umas em português, joinha. Não poderiam ser melhores as traduções críticas que nós estamos fazendo de Espinosa. Mas a referência a línguas estrangeiras é essa. É um pouco, vamos dizer, a ideia de Voltaire de que as viagens formam a juventude. Você vai a outros países de barco, de carro, de avião ou a pé. Você vai a outros lugares por meio dos 
livros. Faz parte da sua formação mesmo. Agora passo a um outro elemento, o da excessiva especialização: eu participei há alguns dias de um simpósio que os alunos de pós-graduação fizeram. A principal queixa, pelo menos no dia em que eu estava, é que a especialização é muito prematura. Começa já na iniciação científica, se mantém com o mestrado e se prolonga no doutorado. E não só essa especialização, como também o aprendizado. A partir do que Margutti colocou, eu queria fazer uma pequena referência a essa questão da especialização precoce, que é a seguinte: a nossa pós-graduação foi implantada durante a ditadura. A partir do programa MEC-USAID, um programa vindo dos Estados Unidos, que dividiu os cursos de graduação em semestrais, introduziu a noção de créditos, disciplinas obrigatórias, disciplinas optativas e a pósgraduação. No nosso caso a pós-graduação foi uma besteira, pelo seguinte: as universidades norte- americanas não especializam naquilo que a gente chama graduação. Elas são cursos de introdução a... Introdução a isso, àquilo... e elas preparam para que a especialização seja a etapa seguinte. Então você faz uma graduação em Ciências Sociais e você vai fazer Direito depois. Não existe curso de Direito. Você faz um curso de Química ou de Física e depois você vai fazer Medicina. Não existe graduação em Medicina, graduação em Direito... Não existem essas graduações. As graduações são uma coisa genérica, que te preparam, para depois você fazer o curso específico. Não era o nosso caso. Nunca foi o nosso caso. Nossas graduações já são específicas. Então como você introduz uma pós-graduação naquilo que já está especificado? Não tem como introduzir. Então você introduz a bobagem, que foi introduzida aqui na pós é o curso de graduação com algumas exigências a mais e alguns créditos a mais. Não sei como acontece nas outras universidades, mas na USP, no início, foi uma tragédia porque você tinha que dar curso de pós-graduação, você não tinha professor para dar isso, você não tinha matérias para dar. E mais: o que se pedia era o professor dar um curso sobre sua própria pesquisa. Muitos de nós ainda estávamos fazendo doutorado, quando fomos dar o curso de pós-graduação, pois a única exigência era que o professor tivesse mestrado. E éramos poucos. Qual era o problema? Por exemplo: estou fazendo uma pesquisa em Espinosa para meu doutorado e sou um dos únicos professores que naquele semestre pode dar um curso de pós, e na minha classe tem um aluno que vai fazer um mestrado sobre Husserl, outro que vai fazer Wittgenstein, outro que vai discutir a questão da acrasia na ética grega, outro... ou seja, cada aluno tem um tema que nada tem a ver com o curso que estou dando, mas ele precisa fazer, coitado, por causa dos malditos créditos em cursos. Assiste a um curso sobre por que um hexâmetro latino de Espinosa definindo a verdade pode ser equiparado ao de Catulo. Eu passei um semestre explicando o que é isso [risos]. Certo? Mas isso não tinha o menor interesse para ninguém. 
Só para mim, que estava alegrinha fazendo aquilo. Então também tem isso. Nós não temos cursos de pós-graduação. Você não tem como ter cursos de pós-graduação, porque a graduação já fez esse papel. Foi uma aberração da ditadura ter importado o modelo estadunidense. Então eu acho que nós lidamos com alguns problemas que decorrem do modo de implantação dos nossos trabalhos. E, só para concluir, uma das outras queixas que os estudantes fizeram é a graduação ter chegado a um tal grau de especificação que os alunos passam um semestre comentando uma vírgula em Aristóteles (eu, pelo menos, comentei o hexâmetro de Espinosa na pós!). A pós-graduação pode fazer esse tipo de coisa. A graduação não pode. Então, como todos colocaram aqui, eu acho que a gente tem que conversar mais, discutir os aspectos positivos e negativos de nossos diferentes cursos. As mazelas de cada um de nós. Discutir com os nossos estudantes, porque só uma discussão como essa nos permitiria caminhar. E a gente não tem feito isso.

\section{[aplausos]}

Ivan Domingues: Paulo vai fazer um pequeno comentário...

Paulo Margutti: É um pequeno comentário, em relação ao que o Marcelo disse, é só o seguinte: a estruturação deste Congresso, bem como a de todos os Congressos de Filosofia que nós tivemos até hoje, refletem um sistema. E é só quando esse sistema mudar é que a estrutura destes Congressos vai mudar também. Enquanto não muda... Tem que mudar! Tá na cara que tem que mudar e eu sinto isso todas as vezes em que eu discuto isso com o público. Antes de mudar, algumas coisas podem ser feitas, para ir minando e sabotando o sistema. Então, um exemplo que eu queria dar é o seguinte: quando eu trabalhava no Departamento de Filosofia da UFMG, a disciplina História da Filosofia do Brasil foi eliminada. Eu não me conformei com isso e criei e paralelamente ao curso um grupo de estudos sobre Filosofia no Brasil. Grupo FIBRA. Então não havia disciplina, mas havia um grupo de alunos interessados que discutia essa questão, já que não havia a disciplina oficial. Então essa é uma forma de sabotar. E é a forma de levar à frente algum projeto. Outra coisa que pode ser feita também é, por exemplo, a seguinte: alguns alunos queriam trabalhar com o pensamento brasileiro, mas é muito difícil você colocar isso em termos de pós-graduação. Em pesquisa de pós-graduação. Então eu sempre dava um jeito; por exemplo, eu orientei dissertação de mestrado sobre aspectos filosóficos em Machado de Assis, aspectos filosóficos em Clarice Lispector, entende? E eu encontro muitos colegas meus divididos. Um, por exemplo, estava muito preocupado porque tinha que estudar Gardner, porque era o que a academia esperava dele era isso. Mas ele queria mesmo era estudar Guimarães Rosa. Aí eu fico empurrando... Deixa de ser bobo, estuda o Guimarães. Vai em frente... As pessoas, muitas vezes, criam coragem e fazem isso. Temos que 
vencer esse receio e ir minando aos poucos. É um limiar. É uma desobediência epistemológica, mas não suficientemente grande para gerar uma repressão violenta. Então, se você faz isso, você consegue. No seu caso, por exemplo, [para fazer o] que você quer pesquisar, você vai ter que tentar achar um orientador um pouco mais flexível, e ver se você consegue negociar as coisas, de maneira a ficar aproximadamente dentro do figurino oficial, mas fazer aquilo que você quer fazer. No momento é o que dá para fazer. De resto, é batalhar e debater em relação a uma alteração radical em relação ao que está acontecendo na nossa pós-graduação. No ensino de Filosofia em geral.

Marilena Chauí: Eu só queria fazer um acréscimo: durante muitos anos, no meu Departamento e em alguns Departamentos no resto do Brasil, o que se dizia com muita tranquilidade era: Marilena não faz Filosofia. Marilena discute política, história, mídia, partido político... Coisas do tipo. Filosofia infelizmente ela não faz. Não faz mais... ela era a nossa esperança, sabe ... [risos] Aí eu publiquei o primeiro volume do Nervura do real. Aí ficou complicado, porque nessa linha do que Paulo disse... Fazer Filosofia, um filósofo e um tema do filósofo... e esgotar o vocabulário e os conceitos desse filósofo... a tarefa estava cumprida... era um filósofo, dois conceitos - estou fazendo o segundo volume agora: fiz a imanência, e agora estou fazendo a liberdade - aí ficou complicado, porque eu entrei no clube de quem fazia Filosofia. Porque fazer Filosofia era aquilo, e aqueles que achavam que fazer Filosofia não era aquilo diziam: Marilena não faz Filosofia mais... porque fazer Filosofia é discutir a política, a sociedade brasileira... etc. Então essas coisas nós temos que discutir, e como vocês sabem nessas coisas eu não presto atenção. Eu sou uma espécie de Dr. Magoo. Não sei se vocês conhecem a figura do Dr. Magoo, o Dr. Magoo anda com o chapeuzinho enterrado na cabeça e toda a desgraceira do mundo vai acontecendo em volta do mundo e ele não vê. Ele passa debaixo de uma escada e a escada acaba de cair, ele dá um passo atrás, formou um buraco, ele não vê nada. Eu sou um pouquinho assim, eu sou o Dr. Magoo. Eu vou levando, eu sei que eu tenho uma má fama dos dois lados de quem acha que Filosofia é uma coisa [...].

FIM DA FITA

Nota:

[Além do restante da fala de Marilena, faltaram os áudios de César, Marcelo, Flávio e Rui. Nossas escusas.] 